Isoconversional Kinetics of Thermally Stimulated Processes 
Sergey Vyazovkin

\section{Isoconversional Kinetics of Thermally Stimulated Processes}

照 Springer 


\author{
Sergey Vyazovkin \\ Department of Chemistry \\ University of Alabama at Birmingham \\ Birmingham \\ Alabama \\ USA
}

ISBN 978-3-319-14174-9

ISBN 978-3-319-14175-6 (eBook)

DOI 10.1007/978-3-319-14175-6

Library of Congress Control Number: 2015930832

Springer Cham Heidelberg New York Dordrecht London

(C) Springer International Publishing Switzerland 2015

This work is subject to copyright. All rights are reserved by the Publisher, whether the whole or part of the material is concerned, specifically the rights of translation, reprinting, reuse of illustrations, recitation, broadcasting, reproduction on microfilms or in any other physical way, and transmission or information storage and retrieval, electronic adaptation, computer software, or by similar or dissimilar methodology now known or hereafter developed.

The use of general descriptive names, registered names, trademarks, service marks, etc. in this publication does not imply, even in the absence of a specific statement, that such names are exempt from the relevant protective laws and regulations and therefore free for general use.

The publisher, the authors and the editors are safe to assume that the advice and information in this book are believed to be true and accurate at the date of publication. Neither the publisher nor the authors or the editors give a warranty, express or implied, with respect to the material contained herein or for any errors or omissions that may have been made.

Printed on acid-free paper

Springer is part of Springer Science + Business Media (www.springer.com) 
To those who believe in the success of hopeless enterprises 


\section{Prologue}

The beginning of philosophy is to know the condition of one's own mind

Epictetus, Golden Sayings: XLVI

I have been developing and using isoconversional kinetics for about 25 years. A little over a decade ago, I started thinking about writing a book on this fascinating topic. However, it was only a year ago that I finally decided to invest my time and effort in actually doing it. My decision was spurred by a dramatic growth of interest in isoconversional kinetics and thus, of the potential audience for this book. In the past three years, (2012-2014) there have been around 2000 publications that use isoconversional methods for kinetic analysis. Barely one third of that number of such papers was published for the same period 10 years ago (2002-2004). That is why now seems like the opportune time for such a book to appear and make an impact.

I discovered isoconversional methods in the late 1980s when I was a graduate student. "Discovered" is really the right word here. Back then, the field of thermal analysis kinetics was ruled by single heating rate methods, and the method of Coats and Redfern was probably an uncrowned king. Like most workers at that time, I followed suit and started working with these methods. It seemed to me that by improving the computational and statistical aspects I could make the single heating rate methods produce unique and reliable kinetic triplets. Ironically, however, the computational and statistical refinement of the methods was making things worse. At that point I realized that the single heating rate methods are flawed beyond repair. The time spent was not entirely wasted, because in the process I learned a great deal of statistical and numerical techniques that I used later in developing isoconversional methodology. The major reason I recognized the fault of the single heating rate methods sooner than many others, was that I did not have the luxury of doing kinetics in the "l'art pour l'art" style. I was given a pragmatic task of finding a way of using thermal decomposition data for kinetic predictions, and the single heating rate methods were systematically failing to make sensible predictions.

The first multiple heating rate method I used was the isoconversional method of Kissinger, Akahira, and Sunose. To my shame, I did not know about the existence of this method. I simply rearranged the Coats-Redfern equation to the isoconversional form and went ahead. While in graduate school, I developed a technique for making isoconversional predictions without estimating the preexponential factor and 
reaction model. I will never forget the sense of wonder when I saw these predictions work! In the early 1990s, I worked out the techniques for isoconversional evaluation of both the preexponential factor and the reaction model. These two techniques completed the computational core of isoconversional kinetics.

Over the years, I and other researchers have done a lot of work on improving the computational tools of isoconversional kinetics. Nevertheless, the main point of my interest has always been finding the link between the dependence of the effective activation energy and the process mechanism. Sometimes this link can be pretty straightforward; at other times it can be very convoluted. However, searching for it is exciting and illuminating every single time. Admittedly, I have learned a great deal of mechanisms and kinetics while trying to understand all kinds of variations in the activation energy. Much of that experience is described in this book.

The book has five chapters. It was my intention to make the book readily accessible to anyone who is familiar with basic (undergraduate) kinetics and thermodynamics. Chapter 1 was written to absorb some of "culture shock" that one may experience on transition from the classical homogenous kinetics to the kinetics of heterogeneous systems studied by the methods of thermal analysis. It provides some basics necessary for comprehension and interpretation of isoconversional kinetics. It also has some practical advice about obtaining computation worthy data.

Chapter 2 describes the computational tools of isoconversional kinetics. The chapter presents the evolution of the methods of estimating activation energy. It emphasizes an important difference between rigid and flexible integral methods. Although implementation of better methods may require significant computational efforts, it is shown that in both, the rigid and flexible categories, there are sufficiently accurate methods that are reducible to the standard linear regression. The chapter also discusses computational techniques for making isoconversional predictions as well as for evaluating the preexponential factors and reaction models.

Chapters 3 and 4 are devoted to the practical application of isoconversional methods to physical and chemical processes respectively. Individual processes are discussed in particular sections of the chapters. The sections are divided into subsections that provide some theoretical background to the particular process and examples of its isoconversional treatment. The physical processes treated in Chap. 3 are the phase transitions in one and two component systems. The one component phase transitions include vaporization and sublimation, glass transition and aging, crystallization and melting of polymers, and morphological solid-solid transitions. The two component phase transitions are the transitions in solutions. They include mixing and demixing, gelation and gel melting, and helix-coil transitions. Chapter 4 deals with the chemical processes most commonly treated by isoconversional methods. These include the processes of polymerization and crosslinking, thermal and thermo-oxidative degradation of polymers, and thermal decomposition of solids. Finally, Chap. 5 is a brief epilogue that collects a few thoughts of mine on the present and future status of isoconversional kinetics.

In conclusion, I would like to acknowledge the luxury of release time I enjoyed while writing this book during the summer and fall semesters of 2014. I thank the National Science Foundation (grant CHE 1052828) and the Department of 
Chemistry for supporting my summer pay and the College of Arts and Sciences and the University of Alabama at Birmingham for granting me a semester of sabbatical leave. I would also like to thank the Thermal Analysis Division of Mettler-Toledo, Inc. for their exemplary commitment to isoconversional kinetics. They have implemented many of the computational tools developed by me as a part of their thermal analysis software known as "model-free kinetics" and have done a great job of popularizing isoconversional kinetics. I am very grateful to them for generously supporting my research for two decades.

Sergey Vyazovkin Birmingham, AL 2014 


\section{Contents}

1 Some Basics En Route to Isoconversional Methodology ....................... 1

1.1 From Condensed-Phase Kinetics to Isoconversional Principle ......... 1

1.2 Understanding Variable Activation Energy ……………………….... 13

1.3 Obtaining Computation-Worthy Data ............................................... 19

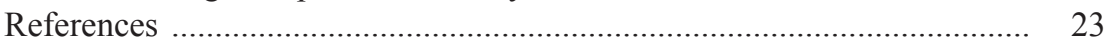

2 Isoconversional Methodology ……………………………………….... 27

2.1 Evolution of Isoconversional Methods ………………..................... 27

2.1.1 Early Methods ……………............................................. 27

2.1.2 Modern Methods ……………………………................... 33

2.2 Estimating Reaction Models and Preexponential Factors ................. 41

2.2.1 Prelude ........................................................................ 41

2.2.2 The Use of the Compensation Effect …………..................... 42

2.2.3 The Use of the $\mathrm{y}(\alpha)$ or $\mathrm{z}(\alpha)$ Master Plots ............................... 47

2.3 Kinetic Predictions ...................................................................... 51

2.3.1 Why Predictions? ............................................................ 51

2.3.2 Model Based Versus Model Free .......................................... 52

2.3.3 Understanding Precision and Accuracy

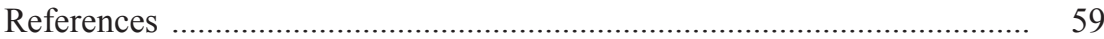

3 Physical Processes ............................................................................. 63

3.1 Phases and Transitions Between Them ………………………….... 63

3.2 Vaporization and Sublimation …………………………………...... 66

3.2.1 Background ................................................................... 66

3.2.2 Isoconversional Treatment .................................................... 69

3.3 Glass Transition ........................................................................... 73

3.3.1 Background ................................................................... 73

3.3.2 Isoconversional Treatment ……………………………....... 78

3.4 Glass Aging …………........................................................... 85

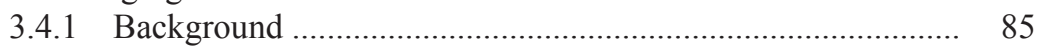

3.4.2 Isoconversional Treatment .................................................... 88

3.4.3 Activation Energies of $\beta$-Relaxation from DSC ………….... 92

3.5 Nucleation ............................................................................ 96 
3.6 Crystallization of Polymers …………………….......................... 102

3.6.1 Background .................................................................... 102

3.6.2 Isoconversional Treatment ................................................... 106

3.7 Melting of Polymers …………………………………………..... 110

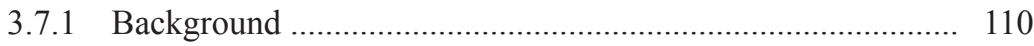

3.7.2 Isoconversional Treatment .................................................... 113

3.8 Solid-Solid Transitions ................................................................ 117

3.8.1 Background....................................................................... 117

3.8.2 Isoconversional Treatment .................................................... 123

3.9 Mixing and Demixing …………………………....................... 125

3.9.1 Background .................................................................. 125

3.9.2 Isoconversional Treatment ..................................................... 130

3.10 Gelation and Gel Melting ……………………............................. 132

3.10.1 Background ................................................................... 132

3.10.2 Isoconversional Treatment of Gelation ................................ 135

3.10.3 Isoconversional Treatment of Gel Melting .......................... 142

3.11 Helix-Coil Transition ................................................................... 148

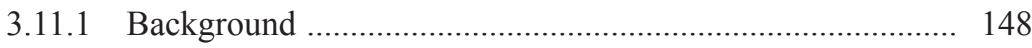

3.11.2 Isoconversional Treatment of Protein Denaturation ............. 151

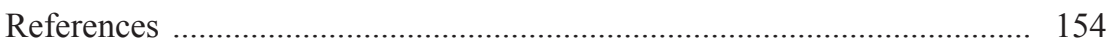

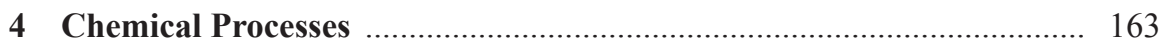

4.1 Introduction ............................................................................. 163

4.2 Polymerization and Cross-Linking ……………………………..... 165

4.2.1 Background to Polymerization .............................................. 165

4.2.2 Isoconversional Treatment of Polymerization ....................... 172

4.2.3 Background to Cross-Linking …………………………...... 176

4.2.4 Isoconversional Treatment of Cross-Linking ........................ 188

4.3 Thermal and Thermo-oxidative Degradation of Polymers ................ 194

4.3.1 Background .................................................................... 194

4.3.2 Isoconversional Treatment .................................................. 197

4.4 Thermal Decomposition of Solids .................................................. 207

4.4.1 Background ........................................................................ 207

4.4.2 Isoconversional Treatment .................................................. 217

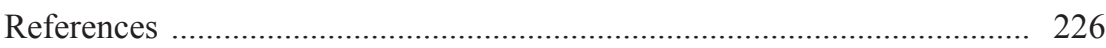

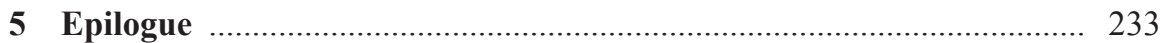

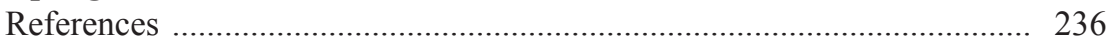

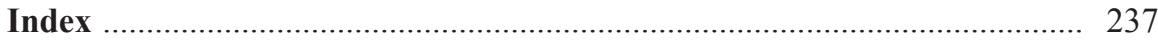




\section{About the Author}

Prof. Sergey Vyazovkin received his Ph.D. from the Byelorussian State University in 1989. He then joined the Institute for Physical Chemistry (Minsk) where he worked until 1993. Since 1993, he had held visiting positions at the Technical University of Vienna, the University of Toledo, and the University of Nice Sophia-Antipolis. Before joining the University of Alabama at Birmingham, he worked in the University of Utah as a research faculty and the deputy director of the Center for Thermal Analysis. His research interests are concerned with the application of thermal analysis methods to thermally stimulated processes in a wide variety of condensed phase systems. He is a winner of the Mettler-Toledo Award in thermal analysis and of the James J. Christensen Award in calorimetry. Prof. Vyazovkin is editor of Thermochimica Acta and a member of the editorial board of Macromolecular Rapid Communications and Macromolecular Chemistry and Physics. He is a member of the American Chemical Society Analytical Division, the North American Thermal Analysis Society, and the International Confederation for Thermal Analysis and Calorimetry.

Department of Chemistry, University of Alabama at Birmingham, Birmingham, AL 35294, USA 